\title{
Grupos de trabalhadores acometidos por LER/DORT: relato de experiência
}

\author{
Camilla de Paula Zavarizzi ${ }^{a}$ (D), Regina Mituyo Matsuo de Carvalho ${ }^{\mathrm{b}}$ (1), \\ Maria do Carmo Baracho de Alencar ${ }^{a}$ (D) \\ aUniversidade Federal de São Paulo - UNIFESP, Santos, SP, Brasil.

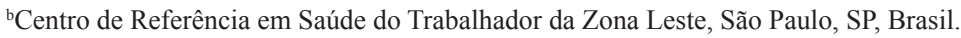

\begin{abstract}
Resumo: Objetivo: O presente artigo teve como objetivo apresentar as experiências de intervenções interdisciplinares em grupos com pacientes acometidos por LER/DORT e atendidos em um CRST do município de São Paulo. Método: Trata-se de um relato de experiência de atendimentos em grupo, durante o período de fevereiro a novembro 2017. Os sujeitos acometidos por LER/DORT eram convidados a participar de grupos com enfoques terapêuticos e educativos, fechados e que ocorriam semanalmente. Houve o registro descritivo de cada encontro e os registros foram posteriormente analisados. Resultados: No período ocorreram 8 grupos com 4 encontros cada e houve participação de 8 trabalhadores em cada grupo, com um total de 67 participantes. Os temas abordados foram: representações sociais sobre o trabalho, a saúde, a doença etc.; saúde e segurança no trabalho e formas de prevenção; LER/DORT e a organização no trabalho; orientação postural, repercussões do adoecimento no cotidiano e formas de ressignificação. A abordagem grupal permitiu que os trabalhadores compartilhassem seus anseios e medos de retornar ao trabalho, além de proporcionar trocas de experiências acerca das dificuldades frente às restrições físicas, incapacidades e vivências de sofrimento. Conclusão: As abordagens grupais possibilitam a criação de estratégias coletivas que potencializam o enfrentamento das dificuldades e favorecem ressignificações das vivências e do sofrimento.
\end{abstract}

Palavras-chave: Transtornos Traumáticos Cumulativos, Saúde do Trabalhador, Reabilitação.

\section{Worker's groups affected by RSI/ WRMSD: report of experience}

\begin{abstract}
Objective: This study aimed to present the experiences of interdisciplinary interventions in groups with patients with RSI/WRMSD attended in a CRST at São Paulo city. Method: This is an experience report of group therapeutic care, performed from February to November 2017. Workers with RSI/WRMSD were invited to participate in groups with therapeutic and educational approach, which were closed and weekly performed. There was a descriptive record of each meeting, and the records were later analyzed. Results: During the period, 8 groups with 4 meetings each occurred. Each group was composed by 8 workers, with a total of 67 participants. The topics covered were: social representations about work, health, illness, etc; health and safety at work and forms of prevention; LER / DORT and organization at work; postural orientation, repercussions of the illness in the daily life and forms of resignification. The group approach allowed workers to share their yearnings and fears of returning to work, as well as providing exchanges of experiences on the difficulties of physical restraints, disabilities as well as experiences of suffering. Conclusion: The group approaches allowed the creation of collective strategies that potentiate the coping of the difficulties and favored resignification of the experiences and the suffering.
\end{abstract}

Keywords: Cumulative Trauma Disorders, Occupational Health, Rehabilitation. 


\section{Introdução}

Trabalhadores de diversos ramos de atividades produtivas estão expostos a riscos de adoecimento por lesão por esforços repetitivos/ distúrbios osteomusculares relacionados ao trabalho - LER/DORT. A LER/DORT representa um grupo de doenças que acomete estruturas musculares, tendíneas, de nervos periféricos, de evolução insidiosa e tendo como principal sintoma dor osteomuscular, geralmente em membros superiores (HOUVET; OBERT, 2013).

Essas lesões podem ser incapacitantes, levando os trabalhadores ao afastamento do trabalho, o qual causa ruptura dos laços e das relaçóes sociais que servem de suportes no cotidiano (RAMOS et al., 2010). Ainda, os trabalhadores afastados por LER/DORT convivem com dores crônicas e apresentam um sentimento de incapacidade para o desempenho de atividades básicas e cotidianas (ALENCAR; OTA, 2011).

A LER/DORT não envolve apenas a dimensão biológica, devendo também ser contempladas, no cuidado aos trabalhadores acometidos por esses agravos, as questóes psicossociais envolvidas no processo de adoecimento, no afastamento do trabalho e no processo de reabilitação. $\mathrm{O}$ caráter multifatorial e complexo dessas lesōes demandam, necessariamente, propostas de intervenção que vão além dos tratamentos clínicos e cirúrgicos tradicionais, principalmente quando se trata dos casos já cronificados (BRASIL, 2012a). Considera-se casos crônicos aqueles em que as experiências da doença se tornam permanentes e acarretam disfunçôes que alteram o cotidiano (TADDEO et al., 2012). Portanto, tratamentos isolados e individualizantes demonstram pouca eficácia nesses casos (MERLO; JACQUES; HOEFEL, 2001), sendo fundamental uma intervenção multi ou interdisciplinar na abordagem da LER/DORT.

A formação de grupos terapêuticos, incluindo atividades de informação, vivências, de caráter pedagógico e/ou psicoterapêutico, podem contribuir para a melhora de quadros de dores osteomusculares (BRASIL, 2012a). Trabalhar com grupos na área da saúde possibilita a inversão da relação vertical, a qual frequentemente ocorre entre o profissional da saúde e o sujeito da sua ação, para relaçôes horizontais, sendo essa uma estratégia facilitadora da expressão das necessidades, expectativas e angústias dos pacientes (SOUZA et al., 2005).

No contexto da saúde pública e em equipe interdisciplinar, o trabalho em grupo vem sendo utilizado como uma estratégia para a educação em saúde (SOUZA et al., 2005). Ainda, para os autores, a intervençáo em grupo tem o objetivo de estimular a reflexão acerca da realidade vivenciada pelos seus membros, que apontem estratégias coletivas de enfrentamento dos desafios e de dar a oportunidade de cada sujeito expressar seu pensamento, opinióes e seu ponto de vista, favorecendo trocas entre seus pares.

A abordagem terapêutica grupal junto aos aspectos psicossociais no adoecimento por LER/DORT vem, gradualmente, ocupando espaço, pois essas lesôes demandam propostas de intervenção que abrangem as significativas alteraçóes impostas na vida cotidiana dos sujeitos, e que trazem sofrimento e incertezas (MERLO; JACQUES; HOEFEL, 2001). A prática de atividades grupais tem sido utilizada nos diversos espaços públicos de saúde, inclusive no Campo da Saúde do Trabalhador e especialmente com sujeitos acometidos por esses distúrbios osteomusculares (ALENCAR, 2015; ALENCAR, 2012; MENDES; LANCMAN, 2010; VARANDAS; TAKACURA; YOSHIE, 2009; PERES, 2006).

Uma intervenção grupal no contexto da reabilitação constitui um espaço potencializador, ao passo que pode desenvolver ou aperfeiçoar a capacidade dos sujeitos em solicitar ajuda, desenvolvendo sentimento de solidariedade a partir do reconhecimento do não estar sozinho, além de trocas, de identificaçôes e de confrontos com as experiências pessoais de cada integrante do grupo, os quais podem favorecer uma ressignificação do adoecimento (SAMEA, 2008). Nas intervenções em grupos, alguns dos objetivos são de que os sujeitos saibam lidar de forma mais autônoma com o seu quadro clínico e que o espaço possa amenizar o sofrimento advindo da doença e da culpabilização pelo adoecimento a eles atribuído (MENDES; LANCMAN, 2010). Além disso, o grupo é um espaço potente para captar questóes relativas à subjetividade, para além do olhar reducionista centrado na doença (SAMEA, 2008).

Dessa forma, este trabalho teve como objetivo descrever as experiências em grupo interdisciplinar com pacientes atendidos em um Centro de Referência em Saúde do Trabalhador -CRST do município de São Paulo, e acometidos por LER/DORT.

\section{Método}

O presente artigo trata-se de um relato de experiência, de abordagem qualitativa, de grupos interdisciplinares e com enfoque terapêutico e educativo com pacientes acometidos por LER/DORT atendidos no CRST da Zona Leste do município 
de São Paulo, durante o período de fevereiro a novembro de 2017.

Os CRSTs compõem a Rede de Atenção à Saúde - RAS, do Sistema Único de Saúde - SUS, são unidades de saúde especializadas em Saúde do Trabalhador. Dispõem de serviços clínico-assistenciais e de vigilância em ambientes e processos de trabalho, além de terem a função de retaguarda técnico-pedagógico para a atenção integral à saúde dos trabalhadores, tanto da iniciativa privada quanto da administração pública, bem como de trabalhadores do setor informal, para a RAS (BRASIL, 2012b). O CRST-Leste, está situado em Itaquera, e é referência para a Rede de Atenção à Saúde da região Leste do município de Sáo Paulo, abrangendo 7 Supervisóes Técnicas de Saúde: Cidade Tiradentes, Ermelino Matarazzo, Guaianases, Itaim Paulista, Itaquera, São Mateus e São Miguel. Em relação à assistência, a equipe é formada pelos seguintes profissionais: enfermeira (2), fisioterapeuta (1), fonoaudióloga (1), psicólogo (1), médico do trabalho (1), médico clínico (1) e terapeuta ocupacional (1). São atendidos trabalhadores que sofreram acidente de trabalho e com suspeitas de doenças relacionadas ao trabalho, os quais são encaminhados pela Rede de Atenção à Saúde através da agenda regulada da rede intersetorial e que nos últimos anos vem atendendo também a demanda espontânea.

No primeiro contato do trabalhador com o serviço é realizado um acolhimento por algum profissional de saúde da equipe multiprofissional, exceto o médico. Durante o período deste estudo, nesse acolhimento foi realizada a coleta de dados sociodemográficos, relacionados à atividade de trabalho atual e pregressa, sobre a queixa de saúde, a demanda principal junto ao serviço e a expectativa do trabalhador. O registro foi feito em uma ficha pré-elaborada pelo serviço. Além disso, esse atendimento visou dar orientaçóes iniciais ao trabalhador, tais como: qual o objetivo do serviço, sobre seus direitos, outros equipamentos da rede de saúde e intersetorial que podem ser acessados, entre outros, bem como contribuir com esclarecimentos que fossem necessários. $\mathrm{O}$ acolhimento aconteceu nos dias em que havia também a consulta médica agendada e/ou era realizado antes da mesma, ou era feito a qualquer momento, quando havia uma procura espontânea no serviço. Após o acolhimento, o trabalhador poderia ser encaminhado para outra especialidade no serviço, de acordo com a demanda do paciente identificada pelo profissional que o atendeu.

A maioria dos trabalhadores que procuraram o serviço era acometida por LER/DORT, e, diante disso, a implantação de uma proposta de atendimento em grupo surgiu da necessidade de abordar os casos para além do tratamento clínico tradicional, visto que entendeu-se que a necessidade de tratar as problemáticas de saúde relacionadas às LER/DORT de forma individualizada e com enfoque apenas biológico centrava o adoecimento no sujeito e trazia uma carga de culpabilização do trabalhador pelo adoecimento. Portanto, a abordagem grupal, nesses casos, visou complementar o atendimento clínico e médico tradicional, no sentido de ampliar as intervençôes para que levassem também em conta os aspectos psicossociais nos processos de adoecimento.

O planejamento do grupo foi realizado por uma equipe multiprofissional entre os profissionais das áreas de terapia ocupacional, fisioterapia e psicologia. Foram discutidos e elaborados os objetivos principais do grupo, o tempo de duraçáo, os temas, a quantidade de encontros e atividades/abordagens grupais para cada encontro. Foi definido inicialmente um roteiro com temas gerais pré-programados em todos os grupos, e foi respeitado as demandas eventuais que surgiram em cada grupo. Os grupos foram fechados e divididos em 4 encontros temáticos, com duração média de 1 hora e 30 minutos e realizados 1 vez por semana. Após a elaboração e planejamentos, os grupos foram conduzidos durante o período de realização pelas profissionais da terapia ocupacional e fisioterapia. As profissionais responsáveis trabalharam os temas dos encontros através de dinâmicas de grupos, com estratégias didáticas envolvendo a utilização de mídias, quadros para anotaçóes, debates e discussóes com os participantes, entre outras. Os encontros aconteceram no auditório da unidade, que era um espaço amplo que também permitiu a realização de atividades corporais e expressivas.

O fluxo para encaminhamento ao grupo se deu após uma avaliação da fisioterapia e/ou terapia ocupacional dos pacientes acometidos por LER/DORT. No caso dos pacientes que foram acolhidos pelo serviço e que não demandaram atendimentos especializados de terapia ocupacional e/ou fisioterapia, o caso era discutido em equipe para a necessidade ou náo de encaminhamento ao grupo de LER/DORT.

No período do estudo participaram dos grupos 67 trabalhadores. Para um melhor controle das frequências dos participantes, em cada encontro era registrado a presença do trabalhador em uma planilha específica, com os dados de identificação dos trabalhadores e número do prontuário. Os resultados e a discussão foram elaborados a partir das impressôes empíricas das profissionais, debatidas a cada encontro e durante a construção desse relato. 


\section{Resultados e Discussões}

Foram encaminhados no período de fevereiro a novembro de 2017 um total de setenta e seis $(\mathrm{n}=76)$ pacientes, sendo que $9(11,8 \%)$ não compareceram em nenhum encontro, e $67(88,2 \%)$ trabalhadores participaram dos grupos. Ocorreram no período oito (8) grupos de quatro (4) encontros, participando em média cerca de oito (8) trabalhadores por grupo. Os participantes eram trabalhadores dos mais diversos ramos profissionais, por exemplo: setor bancário, têxtil, construção civil, educação, saúde, asseio e limpeza, entre outros. Em relação ao gênero, a maioria era do feminino $(\mathrm{n}=43)$, correspondendo a $56,6 \%$ dos trabalhadores.
Percebeu-se que os trabalhadores que foram encaminhados ao grupo, mas náo estavam em atendimentos individuais com fisioterapia e/ou terapia ocupacional, tiveram pouca adesão aos encontros. Acredita-se que esse fato ocorreu pelo pouco vínculo estabelecido com os profissionais que conduziam os encontros em grupo, aspecto que necessitaria de maiores investigaçôes, pois a relação entre profissional e paciente está diretamente relacionada à adesão ao tratamento (TADDEO et al., 2012). Abaixo, na tabela 1, estão apresentados os objetivos, atividades realizadas, e os recursos utilizados em cada encontro.

E abaixo estão apresentadas as sínteses dos encontros em grupo realizados durante o período de 2017.

Tabela 1. Objetivos, atividades realizadas, e os recursos utilizados de cada encontro.

\begin{tabular}{|c|c|c|c|}
\hline Encontros & Objetivos & Atividades & Recursos \\
\hline $1^{\circ}$ encontro & $\begin{array}{l}\text { - Apresentação e integração social } \\
\text { entre os participantes. } \\
\text { - Identificar e compreender as } \\
\text { representações dos papéis } \\
\text { sociais, e em situações de vida } \\
\text { dos trabalhadores. }\end{array}$ & $\begin{array}{l}\text { - Dinâmicas de integração. } \\
\text { - Dinâmica brainstorm: consiste em } \\
\text { uma "tempestade" de ideias, baseadas } \\
\text { nas experiências e nos conhecimentos } \\
\text { adquiridos ao longo da vida de cada um. }\end{array}$ & $\begin{array}{l}\text { - Folhas de papel } \\
\text { sulfite e canetas; } \\
\text { quadro branco e } \\
\text { anotações. }\end{array}$ \\
\hline $2^{\circ}$ encontro & $\begin{array}{l}\text { - Estimular os trabalhadores } \\
\text { para serem multiplicadores } \\
\text { de conhecimentos gerais sobre } \\
\text { segurança e saúde no trabalho. } \\
\text { - Promover reflexões para uma } \\
\text { visão crítica sobre as condições } \\
\text { e a organização do trabalho. }\end{array}$ & $\begin{array}{l}\text { - Atividade com enfoque educativo sobre os } \\
\text { riscos de acidentes de trabalho e agravos } \\
\text { à saúde relacionados ao trabalho em } \\
\text { geral (fatores de risco físico, químico, } \\
\text { biológico, psicossociais e de organização } \\
\text { do trabalho) com utilização de recurso } \\
\text { visual (imagens de trabalhadores exercendo } \\
\text { diversas funções). }\end{array}$ & $\begin{array}{l}\text { - Imagens de } \\
\text { trabalhadores } \\
\text { exercendo } \\
\text { diversas funções. }\end{array}$ \\
\hline $3^{\circ}$ encontro & $\begin{array}{l}\text { - Promover conhecimentos } \\
\text { específicos sobre LER/DORT. } \\
\text { - Inverter a lógica da culpabilização } \\
\text { individual pelo adoecimento } \\
\text { por LER/DORT. }\end{array}$ & $\begin{array}{l}\text { - Após apresentação de material audiovisual } \\
\text { e de impressos informativos sobre } \\
\text { LER/DORT foram realizadas discussões } \\
\text { sobre os riscos específicos, as doenças } \\
\text { mais comuns, o papel da organização do } \\
\text { trabalho na etiologia desses distúrbios. } \\
\text { - Informações gerais sobre legislação } \\
\text { previdenciária e trabalhistas de acordo com } \\
\text { as demandas que surgiam da discussão } \\
\text { do grupo. } \\
\text { - Debate sobre formas de superar os desafios } \\
\text { do afastamento do trabalho, retorno ao } \\
\text { trabalho e/ou desemprego. }\end{array}$ & $\begin{array}{l}\text { - Vídeo sobre } \\
\text { LER/DORT } \\
\text { e impressos } \\
\text { informativos. } \\
\text { - Quadro branco }\end{array}$ \\
\hline $4^{\circ}$ encontro & $\begin{array}{l}\text { - Discutir sobre a repercussão } \\
\text { da doença no cotidiano. } \\
\text { - Realizar orientações posturais } \\
\text { e de hábitos em geral que } \\
\text { podem contribuir para evitar } \\
\text { a sobrecarga física e evitar } \\
\text { recidivas de sintomas e o } \\
\text { agravamento da LER/DORT. }\end{array}$ & $\begin{array}{l}\text { - Por meio de exemplos práticos, interpretações } \\
\text { e uso de imagens ilustrativas os trabalhadores } \\
\text { foram orientados sobre as atividades de } \\
\text { vida diária e de vida prática, para serem } \\
\text { realizadas com menor dispor de energia } \\
\text { e com respeito aos limites físicos para } \\
\text { evitar agravamento do quadro clínico. } \\
\text { - Realização de alguma atividade corporal, } \\
\text { expressiva ou dinâmica de grupo que fizesse } \\
\text { analogia com alguma situação vivenciada } \\
\text { no trabalho ou cotidiano para reflexões. }\end{array}$ & $\begin{array}{l}\text { - Imagens ilustrativas } \\
\text { com ex emplos } \\
\text { corretos e incorretos } \\
\text { sobre postura. } \\
\text { - Diversos objetos } \\
\text { domésticos e } \\
\text { ferramentas para } \\
\text { simulações }\end{array}$ \\
\hline
\end{tabular}


Nos encontros do $1^{\circ}$ dia, identificou-se que para a maioria dos participantes o trabalho era a principal e mais importante ocupação que desempenhavam antes do adoecimento. De acordo com os relatos, trabalhar se desdobrava em tentar conseguir desempenhar os outros papéis sociais e atividades de lazer.

O tema trabalho também surgiu como um valor moral, como um dever, pois finalizar um trabalho bem feito trazia uma satisfação e sensação de "missão cumprida", mesmo com a presença de sintomas osteomusculares. Este fato trouxe reflexôes sobre o presenteísmo. O Presenteísmo (trabalhar doente), corresponde a corpos que se sujeitam devido a necessidade de um salário, a falta de oportunidades em outras áreas, o sentimento de responsabilidade e de ter que cumprir bem sua atividade e a naturalização das más condiçôes de trabalho (DALE; DIAS, 2018). E no caso de uma situação de não trabalho, ou seja, desemprego ou afastamento do trabalho, na maioria dos grupos houve sentimento de inutilidade e de isolamento, aliada à perda do prestígio social, pois o afastamento do trabalho pode trazer sofrimento a medida que o sujeito náo exerce um papel socialmente aceito, o de trabalhador, de provedor da família (ALENCAR; OTA, 2011). Na maioria dos grupos ocorreu, nesse momento, a tomada de consciência de que a dedicação total ao trabalho, muitas vezes, contribuiu para o distanciamento de atividades em família e abandono de atividades de lazer, como por exemplo, jogar futebol aos fins de semana, de atividades artesanais que aprenderam com familiares, entre outros. As LER/DORT reduzem a qualidade de vida dos trabalhadores, principalmente no que se refere aos aspectos psicológicos e sociais (PAULA et al., 2016).

Sobre o lazer, os trabalhadores referiram poucas vivências com esse tipo de atividade e geralmente alegavam a falta de tempo e dificuldades financeiras para justificar a ausência dessas atividades. No caso das mulheres, principalmente, ficou evidente a questão da dupla jornada de trabalho como um dos fatores de não realizar atividades de lazer. No estudo de Farias e Araújo (2011) a ausência de participação em atividades de lazer foi associada à prevalência de transtornos mentais comuns. Ainda, para os mesmos autores, a ausência de tempo livre, em função da carga de trabalho, da dupla jornada de trabalho e falta de condição financeira são aspectos que comprometem o acesso ao lazer.

Portanto, estimular os trabalhadores para que busquem outros suportes sociais que auxiliam no enfrentamento de situações difíceis da vida, como centros de convivências, instituições que ofereçam atividades e cursos gratuitos, levantar junto aos trabalhadores espaços possíveis para a prática de lazer e demais locais que favoreçam o convívio social e desenvolvimento de potencialidades, entre outros, são uma das formas possíveis de manutenção do bem-estar social e saúde mental.

Também, os trabalhadores mencionaram que a saúde teve importância para conseguirem se manter trabalhando, apesar de custos físicos e da presença dos sintomas osteomusculares. Geralmente consideravam que ter saúde era como algo que permitia ter uma disposição para conseguir trabalhar, mas que era necessário também ter acesso às consultas médicas e tratamentos no início de qualquer suspeita de doença, além da oferta de medicamentos. As profissionais responsáveis buscavam direcionar as discussões no sentido de estimular a construção de um significado de saúde mais amplo, ou seja, compreendendo não no sentido de ausência de doença, mas de qualidade de vida e com abordagens biopsicossociais envolvidas.

Ao final, os trabalhadores mencionaram que não se consideravam pessoas "doentes", porém, muitas vezes, sentiam-se incapazes de realizar o trabalho da forma que realizavam antes do adoecimento, ou seja, com agilidade e reconhecimento social. Essa situação corrobora com os achados de Toldrá et al. (2010), que apesar dos trabalhadores do estudo referirem melhoras dos sintomas osteomusculares, a maioria manteve a incapacidade para desempenhar as mesmas atividades exercidas antes do acidente ou do início da doença. Para as mesmas autoras, as LER/DORT geram incapacidades nas atividades que exigem mobilidade, cuidado pessoal, e nas atividades da vida doméstica em geral, afetando as áreas principais da vida (educação, trabalho, emprego, vida econômica, comunitária, social e cívica). Nesse primeiro encontro também foi identificado angústias referentes ao processo de retorno ao trabalho, pois, os trabalhadores temiam não ser compreendidos quanto as suas limitaçóes físicas. Para Pestana et al. (2017), existem muitas barreiras para o retorno ao trabalho e os trabalhadores temem o desrespeito às restriçóes físicas impostas pela doença, o assédio moral, e o risco iminente de demissão.

Nos encontros do $2^{\circ}$ dia de grupo os trabalhadores tiveram oportunidade de obter novos aprendizados sobre segurança e saúde no trabalho e compartilhar conhecimentos pessoais de acordo com as vivências em seus próprios trabalhos. Nesta atividade os trabalhadores eram estimulados a identificar possíveis formas de acidentes ou adoecimento relacionados ao trabalho, a sugerir medidas ou meios de prevenção, bem como fazer relaçôes com seus próprios trabalhos. Ao observar as imagens, os trabalhadores debateram sobre o que eles identificavam como riscos à segurança 
e à saúde no trabalho e o que poderiam fazer para se adequarem em relação ao uso de equipamentos de proteção individual (EPI), mudanças de postura, mobiliário, no processo de trabalho, bem como da organização do trabalho. Alguns trabalhadores questionavam porque a própria empresa, muitas vezes, não lhes forneciam informaçôes para a prevenção de acidentes e/ou promoção da saúde no trabalho. Segundo Abareshi et al. (2015), intervençôes educativas no ambiente de trabalho com enfoque ergonômico podem reduzir o risco de adoecimento por LER/DORT e contribuir na melhora da produçáo. Entretanto, o empregador não deve estar isento das responsabilidades de garantias de saúde e segurança aos trabalhadores. Sobre os modos de educação em saúde, cabe ressaltar que devem destinar-se à formação da consciência crítica e a autonomia dos sujeitos, tendo em vista que o objetivo final da educação não é apenas a compreensão da informação, mas de incentivar as pessoas a definir os seus próprios problemas, encontrar soluçóes e lidar de forma eficaz (TADDEO et al., 2012).

Nesse encontro era possível proporcionar uma visão mais ampla sobre a etiologia dos agravos à saúde relacionados ao trabalho e promover a conscientizaçâo de que algumas medidas, principalmente relacionadas à organizaçáo do trabalho, poderiam ajudar na redução dos mesmos.

Nos encontros do $3^{\circ}$, foram debatidos conteúdos específicos sobre a LER/DORT e problematizado junto aos trabalhadores as relaçóes do adoecimento com os seus processos e organizaçáo do trabalho. Embora alguns trabalhadores mencionassem que já haviam realizado essas relaçôes, ocorriam, muitas vezes, situaçôes de desconfiança dos profissionais de saúde, pois alguns questionaram se realmente era um problema relacionado trabalho, visto a dupla jornada de trabalho no caso das mulheres ou ainda pela presença de fatores pessoais como idade e o peso corporal, entre outros. Para Fernandes (2011) as atividades domésticas não podem ser fator excludente da relação de doenças osteomusculares com o trabalho, pois as mulheres estáo mais expostas aos processos de precarização do trabalho.

Em relação ao diagnóstico, muitos trabalhadores demonstravam estranhamento com seus corpos, pois não compreendiam a invisibilidade da dor, o desconforto e as dificuldades no cotidiano. O pouco conhecimento sobre sua doença pareceu ser um aspecto gerador de sofrimento. O desconhecimento por parte dos trabalhadores de seus problemas de saúde e dos meios disponíveis para a promoção da saúde e prevenção de doenças também foi constatado no estudo de Sanches et al. (2010), a partir dos relatos de trabalhadores membros de uma associação de portadores de LER/DORT. O empoderamento do paciente e o autocuidado são formas eficazes para lidar com as doenças crônicas, permitindo que o paciente tome uma consciência crítica em relação a seus problemas de saúde (TADDEO et al., 2012). Apesar de não serem desenvolvidas açóes direcionadas para o retorno ao trabalho dos participantes, detectou-se o medo dos trabalhadores frente à iminência da alta do INSS e este foi um tema frequentemente discutido. Os trabalhadores temiam retornar ao trabalho, em função da possibilidade de não serem aceitos por colegas e de não terem suas restriçóes físicas respeitadas. Os trabalhadores compartilharam as angústias referente às incertezas do mercado de trabalho e quanto à recolocação profissional. Esse sofrimento era presente mesmo para aqueles que ainda estavam contratados, pois temiam perder o emprego devido a presença da doença e por não se considerarem produtivos como anteriormente. $\mathrm{O}$ retorno ao trabalho dos trabalhadores com LER/DORT é considerado uma situação complexa, na qual há diversas barreiras e que ainda não se tem a devida atenção das autoridades (TOLDRÁ et al., 2010; SALDANHA et al., 2013; PESTANA et al., 2017). Houve reflexóes sobre construção de ideias e formas de enfrentamento e ressignificação do adoecimento: escolarização, capacitação, importância sobre conhecer os direitos, ocupar espaços coletivos na comunidade e como isso poderia favorecer no enfrentamento do medo do desemprego, por exemplo.

Também, o modo de atendimento dos peritos do INSS foi considerado, pelos participantes, inadequado durante as perícias, e os mesmos citaram a existência frequente de situações constrangedoras, humilhantes e intimidadoras. Essas situaçóes junto aos peritos foram relatadas por trabalhadores em outros estudos (ALENCAR; OTA, 2011; ZAVARIZZI; ALENCAR, 2014).

Nos encontros do $4^{\mathrm{o}}$ dia, foi debatido o modo como as atividades são executadas (movimento, postura e ritmo), e sobre as atividades que não são realizadas devido a presença de sintomas de dor. Os trabalhadores eram incentivados a não deixarem de realizar as suas atividades prazerosas e que refletissem sobre formas diferentes de execução e/ou a possibilidade de substituiçóes de atividades que pudessem proporcionar algum prazer. Era esperado reflexôes e críticas entre os trabalhadores sobre seus fazeres no cotidiano, que mobilizassem para possíveis mudanças de hábitos e que contribuíssem para uma melhor qualidade de vida, além de trocas de experiências e sobre mudanças de hábitos já 
implantadas no cotidiano dos trabalhadores, autoconhecimento de limites e potencialidades.

Eram identificadas as estratégias utilizadas para minimizar os sintomas osteomusculares e com objetivo de compartilhar as vivências e experiências, além de obter orientaçôes dos profissionais. As doenças crônicas exigem um tratamento permanente, dessa forma é necessário que os sujeitos tenham hábitos e atitudes que promovam a consciência para o autocuidado e para corresponsabilização no tratamento (TADDEO et al., 2012). Também eram incentivadas reflexóes sobre a corresponsabilidade sobre suas condiçôes de saúde, como exemplos, buscando sempre ter uma alimentação saudável, praticando atividade física, entre outros. Para Torres (2013) os profissionais de saúde têm o dever de orientar os trabalhadores adoecidos por LER/DORT quanto ao autocuidado e de melhorar o modo de realização de suas rotinas, para que os mesmos sejam corresponsáveis pelo próprio cuidado e pelo sucesso de sua recuperação.

Na maioria dos grupos ocorreram problematizaçôes sobre as impossibilidades e/ou dificuldades de seguir as orientações oferecidas durante os encontros para aplicaçáo nos locais de trabalho. Muitas das orientaçôes referiam-se a mudanças na organização do trabalho, como, por exemplo, a realização de pausas durante a jornada, a flexibilização das cobranças por produtividade e a diminuição de horas extras, cuja negociação era difícil com as empresas. Além disso, as orientaçóes posturais e de redução de sobrecargas osteomusculares, que foram compartilhadas no último encontro, também esbarravam na impossibilidade da empresa em realizar as mudanças necessárias, como, por exemplo, a aquisiçáo de cadeira adequada ou substituição de ferramentas obsoletas, entre outros. No mundo capitalista o trabalhador perde o poder e a autonomia sobre o seu próprio corpo, sem os subsídios necessários para cumprir suas atividades de forma adequada e confortável tendo que se submeter a atividades que, muitas vezes, favorecem o adoecimento do seu corpo e ainda oprimem a sua singularidade e a capacidade de criação (DALE; DIAS, 2018).

\section{Considerações Finais}

A abordagem grupal em Saúde do Trabalhador realizada permitiu que os trabalhadores compartilhassem as ansiedades e os medos diante das dificuldades e desafios encontrados, possibilitando a criação de estratégias individuais e coletivas que potencializam o enfrentamento e a ressignificação do sofrimento. Ressalta-se que a escuta empática e qualificada dos profissionais nesse momento foi importante para o fortalecimento de vínculo e de relações de confiança entre os participantes e profissionais que conduziram os encontros.

Foi possível refletir com os trabalhadores que as LER/DORT são de caráter coletivo e social, ou seja, são fortemente influenciadas pelas formas de organização do trabalho na atualidade e pelas condiçôes de vida e trabalho, invertendo a lógica que individualiza o adoecimento e culpabiliza o trabalhador. Embora essa abordagem não tenha contribuído diretamente para o processo de retorno ao trabalho, observou-se que ao final do grupo os trabalhadores se expressaram de forma mais esperançosa em relação a isso. Além disso, demonstraram ter um maior conhecimento sobre o seu diagnóstico clínico, além de autoconhecimento e respeito às suas restriçóes físicas no cotidiano, e passaram a refletir de forma mais reflexiva e crítica sobre as condições de vida e de trabalho na atualidade.

Ao final, verificou-se que para que haja adesão dos pacientes que não estão em atendimentos individuais de fisioterapia e/ou terapia ocupacional também é necessário o engajamento e encaminhamento da equipe médica, com incentivo aos pacientes para a participação nos encontros em grupo. Outro aspecto importante ressaltado e sugerido é a implantação de alguma avaliaçáo sobre a qualidade de vida e capacidade funcional dos participantes, para melhor evidência clínica dos resultados obtidos.

Esse relato de experiência pode ter limitaçôes, pois refere-se às impressóes dos profissionais apreendidas através dos relatos e verbalizaçóes dos trabalhadores ao longo dos grupos realizados. Contudo, espera-se estimular as intervençôes em abordagens grupais e com enfoques biopsicossociais nos serviços de Saúde do Trabalhador, visando a atençáo integral para os sujeitos acometidos por LER/DORT.

\section{Referências}

ABARESHI, F. et al. Educational intervention for reducing work-related musculoskeletal disorders and promoting productivity. International Journal of Occupational Safety and Ergonomics, Abingdon, v. 21, n. 4, p. 480-485, 2015.

ALENCAR, M. C. B. Aspectos relacionados aos afastamentos do trabalho por LER/Dort. Relato de experiência no Cerest-Santos. In: SIMONELLI, A. P.; RODRIGUES, D. S. Sauide e trabalho em debate: velhas questôes, novas perspectivas. Brasília: Paralelo 15, 2012. p. 267-285.

ALENCAR, M. C. B. Intervençóes da Terapia Ocupacional junto aos sujeitos afastados do trabalho por LER/DORT. Cadernos de Terapia Ocupacional da UFSCar, São Carlos, v. 23, n. 4, p. 889-898, 2015. 
ALENCAR, M. D. C. B.; OTA, N. H. O afastamento do trabalho por LER/DORT: repercussóes na saúde mental. Revista de Terapia Ocupacional da Universidade de São Paulo, São Paulo, v. 22, n. 1, p. 60-67, 2011.

BRASIL. Ministério da Saúde. Departamento de Vigilância em Saúde Ambiental e Saúde do Trabalhador. Dor relacionada ao trabalho: lesóes por esforços repetitivos (LER): distúrbios osteomusculares relacionados ao trabalho (DORT). Brasilia: Ministério da Saúde, 2012a.

BRASIL. Portaria $n^{\circ} 1.823$ de 23 de agosto de 2012. Institui a Política Nacional de Saúde do Trabalhador e da Trabalhadora. Diário Oficial [da] República Federativa do Brasil, Poder Executivo, Brasília, DF, 23 ago. 2012b.

DALE, A. P.; DIAS, M. D. A. A “extravagancia” de trabalhar doente: o corpo no trabalho em individuos com diagnostico de LER/DORT. Trabalho, Educação e Saúde, Rio de Janeiro, v. 16, n. 1, p. 263-282, 2018.

FARIAS, M. D.; ARAÚJO, T. M. Transtornos mentais comuns entre trabalhadores da zona urbana de Feira de Santana-BA. Revista Brasileira de Saúde Ocupacional, São Paulo, v. 36, n. 123, p. 25-39, 2011.

FERNANDES, R. C. P. Precarização do trabalho e os distúrbios musculoesqueléticos. Caderno CRH, Salvador, v. 24, p. 153-167, 2011. Número Especial.

HOUVET, P.; OBERT, L. Upper limb cumulative trauma disorders for the orthopaedic surgeon. Orthopaedics \& Traumatology: Surgery \& Research, France, v. 99, n. 1, p. 104-114, 2013.

MENDES, L. F.; LANCMAN, S. Reabilitação de pacientes com LER/DORT: contribuições da fisioterapia em grupo. Revista Brasileira de Saúde Ocupacional, São Paulo, v. 35, n. 121, p. 23-32, 2010.

MERLO, Á. R. C.; JACQUES, M. G. C.; HOEFEL, M. G. L. Trabalho de grupo com portadores de LER/DORT: relato de experiência. Psicologia: Reflexão e Crítica, Porto Alegre, v. 14, n. 1, p. 253-258, 2001.

PAULA, E. A. et al. Qualidade de vida de trabalhadores com LER/DORT e lombalgia ocupacional atendidos no Cerest de Guarulhos, São Paulo. Revista Brasileira de Saúde Ocupacional, São Paulo, v. 41, p. 1-11, 2016.

PERES, C. C. Ações coletivas para prevenção de Ler/Dort. Boletim da Saúde, Porto Alegre, v. 19, n. 1, p. 39-50, 2006.

PESTANA, B. M. et al. O retorno ao trabalho de sujeitos acometidos por LER/DORT. Cadernos Brasileiros de
Terapia Ocupacional, São Carlos, v. 25, n. 4, p. 735$742,2017$.

RAMOS, M. Z. et al. Trabalho, adoecimento e histórias de vida em trabalhadoras da indústria calçadista. Estudos de Psicologia, Natal, v. 15, n. 2, p. 207-215, 2010.

SALDANHA, J. H. S. et al. Facilitadores e barreiras de retorno ao trabalho de trabalhadores acometidos por LER/ DORT. Revista Brasileira de Saúde Ocupacional, São Paulo, v. 38, n. 127, p. 122-138, 2013.

SAMEA, M. O dispositivo grupal como intervenção em reabilitação: reflexões a partir da prática em Terapia Ocupacional. Revista de Terapia Ocupacional da Universidade de São Paulo, São Paulo, v. 19, n. 2, p. 85-90, 2008.

SANCHES, E. N. et al. Organização do trabalho, sintomatologia dolorosa e significado de ser portador de LER / DORT. Psicologia Argumento, Curitiba, v. 28, n. 63, p. 313-324, 2010.

SOUZA, A. C. et al. A educação em saúde com grupos na comunidade: uma estratégia facilitadora da promoção da saúde. Revista Gaúcha de Enfermagem, Porto Alegre, v. 26, n. 2, p. 147-153, 2005.

TADDEO, P. S. et al. Acesso, prática educativa e empoderamento de pacientes com doenças crônicas. Ciência \& Saúde Coletiva, Rio de Janeiro, v. 17, n. 11, p. 2923-2930, 2012.

TOLDRÁ, R. C. et al. Facilitadores e barreiras para o retorno ao trabalho: a experiência de trabalhadores atendidos em um centro de referência em saúde do trabalhador - SP, Brasil. Revista Brasileira de Saúde Ocupacional, São Paulo, v. 35, n. 121, p. 10-22, 2010.

TORRES, A. R. A. Linha de cuidado em saúde do trabalhador: uma tecnologia para a organização do cuidado ao trabalhador com LER/DORT. 2013. 154 f. Dissertação (Mestrado em Saúde da Família) - Universidade Federal do Ceará, Sobral, 2013.

VARANDAS, D. M.; TAKACURA, R.; YOSHIE, R. Atividades terapêuticas na abordagem grupal em saúde do trabalhador. Saúde Coletiva, São Paulo, v. 34, n. 6, p. 255-258, 2009

ZAVARIZZI, C.; ALENCAR, M. C. B. Aspectos relacionados ao afastamento de bancários por LER/DORT. Cadernos de Terapia Ocupacional da UFSCar, São Carlos, v. 22, n. 3, p. 487-496, 2014.

\section{Contribuição dos Autores}

Camilla participou da realização dos grupos, da obtenção, análise e discussão e interpretação dos dados, além da elaboração e revisão do artigo. Regina participou da realização dos grupos, da obtenção, análise e discussão dos dados e interpretação do artigo. Maria do Carmo participou da análise, discussão e interpretação dos dados, além da revisão do artigo. Todas as autoras aprovaram a versão final do texto. 